\title{
Beneficial Effects of Enteral Fat Administration on Liver Dysfunction, Liver Lipid Accumulation, and Protein Metabolism in Septic Rats
}

\author{
Naoki Hayashi, * Norio Kashiwabara, Daiji Yoshihara, \\ Yasuyoshi Takeshita, Harumi Handa, Minoru YanaI, ${ }^{1}$ \\ June MAEDA, ${ }^{2}$ and Mitsuru YamaKAWA ${ }^{2}$ \\ Research Institute of Life Science, Snow Brand Milk Products, Co., Ltd., \\ Shimotsuga, Tochigi 329-05, Japan \\ ${ }^{1}$ Nutritional Science Laboratory, Snow Brand Milk Products, Co., Ltd., \\ Saitama 350-11, Japan \\ ${ }^{2} 3$ rd Department of Surgery, University of Tokyo, \\ Tokyo 112, Japan
}

(Received July 4, 1995)

Summary The purpose of this study was to examine the effect of different amounts of fat in enteral diets on liver function, liver lipid accumulation, and protein metabolism in septic rats. Sepsis was induced in Wistar rats by cecal ligation and puncture. The rats were divided into four groups and were fed enterally $0 \%(\mathrm{~F} 0, n=7), 10 \%(\mathrm{~F} 10, n=7)$, $20 \%(\mathrm{~F} 20, n=8)$, or $30 \%(\mathrm{~F} 30, n=9)$ of total calories as fat. The liquid diet consisted of medium-chain and long-chain triglyceride mixtures as the fat sources, casein oligopeptide, and dextrin $(100 \mathrm{kcal} / 100 \mathrm{ml})$. Intraduodenum feeding was ended on the 6th day. Serum glutamic oxaloacetic transaminase and glutamic pyruvic transaminase activities, indices of liver dysfunction, were highest in the F0 group, and triglycerides accumulated in the livers of that group, possibly because of the large proportion of carbohydrate in the diet. Value of nitrogen balance was highest in the $F$ 10 group, and serum total protein and albumin concentration were higher in the F10 and F20 groups than in the F0 and F30 groups. The liver protein content in the F10 and F20 groups was higher than in the F0 and F30 groups. Serum triglyceride in the F30 group was about 2 times higher than in the F10 and F20 groups. These results indicate that enteral fat administration in septic rats as $30 \%$ of total calories reduced liver dysfunction and liver triglyceride accumulation, but might have been excessive for optimal protein metabolism. Therefore, the preferable amount may range from $10 \%$ to $20 \%$ of total calories.

Key Words enteral fat administration, septic rats, liver dysfunction, liver

* To whom correspondence should be addressed. 
lipid accumulation, protein metabolism, liver protein

In septic patients suffering from severe infections such as peritonitis, an energy expenditure increase of more than $60 \%$ and a typical energy insufficiency occur. Septic patients, therefore, require a high-calorie diet (1).

Usually, fats are a more effective energy source than carbohydrates and proteins because of their high caloric value, but several investigators consider fat administration ineffective in sepsis because carnitine, which is indispensable for fat oxidation, decreases markedly in the muscle and plasma of septic patients $(2,3)$, and lipase activity, which is essential for fat hydrolysis, decreases in muscle and liver $(4,5)$. Besides, liver lipid accumulation $(6,7)$ and liver dysfunction $(7,8)$ are observed frequently in sepsis. In contrast, recent observations showed that septic patients and animals utilized fat as an energy source preferentially $(9,10)$. The effects of fat and the optimal fat/carbohydrate ratio in sepsis still remains controversial.

In this study, we used septic rats to investigate the effects of different proportions $(0-30 \%$ of total calories) of fats in enteral diets on liver lipid accumulation, liver dysfunction, and protein metabolism. Medium-chain triglyceride (MCT)-rich oil was used as the fat source because its absorption and oxidation is very rapid even in the absence of carnitine (11), and MCT is a superior energy source compared to long-chain triglycerides in the septic rat (12).

\section{MATERIALS AND METHODS}

Experimental animals. Forty six-week-old male Wistar rats were purchased from Charles River Japan, Inc. (Yokohama, Japan). They weighed about $250 \mathrm{~g}$ each, and were housed individually in a feeding room with a temperature of $23 \pm$ $2{ }^{\circ} \mathrm{C}$ and a light/dark cycle of $12 \mathrm{~h}$ (from $07: 00$ to $19: 00 \mathrm{~h}$ ). Each rat was given a commercial diet (CRF-1, Oriental Co., Tokyo) and tap water ad libitum. The rats were divided into 4 groups and were randomized by weight.

Preparation of the septic rats. The following was prepared as a septic model with severe infection. After an 8-h fast, sepsis was induced by cecal ligation and puncture as described by Wichterman et al. (13). The laparotomy was performed through a midline incision under pentobarbital anesthesia $(0.8 \mathrm{ml} / \mathrm{kg}$, i.p. $)$. The cecum was filled with feces by milky stool back from the ascending colon. After ligation of the cecum just below the ileocecal valve, the ligated part was punctured twice with an 18-gauge needle and the bowel was replaced in the peritoneal cavity and the abdomen was closed with a two-layer suture. Postoperatively, the rats received saline subcutaneously $(5 \mathrm{ml} / 100 \mathrm{~g}$ body weight). Sixteen hours after the operation, the necrotic cecum was removed to permit recovery from the potentially lethal peritonitis, and a catheter ( 5 Fr size umbilical catheter, Nippon Sherwood Medical Ind., Tokyo) was inserted from the stomach into the duodenum for enteral 


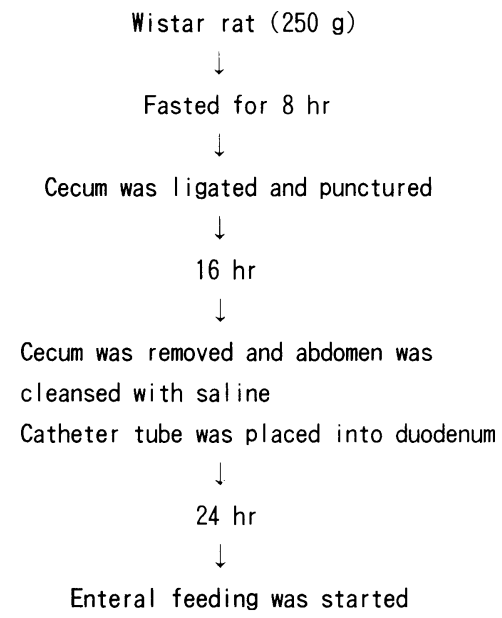

Fig. 1. Preparation method of septic animals.

feeding under pentobarbital anesthesia (Fig. 1). The catheter was tunneled subcutaneously to exit outside the body at the back and connected to a continuous infusion pump through the protective coil under the swivel device. Each rat was fasted for $24 \mathrm{~h}$ to simulate the initial recovery period of postoperative patients, who receive almost no food.

Experimental diets and enteral feeding. The four groups of rats were fed liquid diets containing different amounts of fat, as follows: $0 \%$ (F0 group), 10\% (F10 group), 20\% (F20 group), and 30\% (F30 group) of total calories. The composition of the diets and of the fat are shown in Tables 1 and 2, respectively. A medium-chain triglyceride and safflower oil (long-chain triglyceride) mixture (both from Nissin Oil Mills, Ltd., Tokyo) was the fat source, and the safflower oil supplied the linoleic acid, an essential fatty acid. Casein oligopeptide (made in our institute at Snow Brand Milk Products Co., Ltd., Tokyo) was the nitrogen source (22\% total calories), and total calories were adjusted to $100 \mathrm{kcal} / 100 \mathrm{ml}$ with dextrin. All diets were supplemented daily with the same amount of a balanced electrolyte and vitamin mixture.

Intraduodenal feeding was initiated at $25 \mathrm{kcal} / \mathrm{day} 24 \mathrm{~h}$ after surgery, the $1 \mathrm{st}$ postoperative day (POD). The calories were increased daily up to $75 \mathrm{kcal} / \mathrm{day}$ on POD 5. Enteral feeding was continued to POD 6 (Table 3). No severe diarrhea was observed.

Protein metabolism and nutritional effects. Body weights were measured at the same time each day throughout the experiment. Total urine and feces were collected for each animal every day. The daily nitrogen balance was calculated by subtracting urinary and fecal nitrogen from dietary nitrogen. For the measurement of urinary and fecal nitrogen, a semi-micro Kjeldahl method was used with the Kjeltec auto analyzer (MODEL 1030, Tecator, Sweden). 
Table 1. Composition of the experimental liquid diets for enteral feeding.

\begin{tabular}{|c|c|c|c|c|c|}
\hline & & F0 & F10 & F20 & F30 \\
\hline \multicolumn{2}{|c|}{$\begin{array}{l}\text { Fat }(\mathrm{g} / 100 \mathrm{kcal}) \text { (as safflower oil } \\
\text { and } \mathrm{MCT}^{*} \text { mixture) }\end{array}$} & 0 & 1.1 & 2.3 & 3.4 \\
\hline \multicolumn{2}{|l|}{$\begin{array}{l}\text { Carbohydrate }(\mathrm{g} / 100 \mathrm{kcal}) \\
\quad \text { (as dextrin) }\end{array}$} & 19.4 & 16.9 & 14.3 & 11.8 \\
\hline \multicolumn{2}{|l|}{$\begin{array}{l}\text { Protein }(\mathrm{g} / 100 \mathrm{kcal}) \\
\quad(\text { as casein peptides })\end{array}$} & 5.6 & 5.6 & 5.6 & 5.6 \\
\hline \multirow{3}{*}{\multicolumn{2}{|c|}{$\begin{array}{l}\% \text { of kcal from fat } \\
\% \text { of kcal from carbohydrate } \\
\% \text { of kcal from protein }\end{array}$}} & 0 & 10 & 20 & 30 \\
\hline & & 78 & 68 & 58 & 48 \\
\hline & & 22 & 22 & 22 & 22 \\
\hline Electrolytes & \multicolumn{5}{|c|}{$\begin{array}{l}\mathrm{Na} 74.9 \mathrm{mg}, \mathrm{K} 140.4 \mathrm{mg}, \mathrm{Ca} 52.1 \mathrm{mg}, \mathrm{Mg} 17.4 \mathrm{mg}, \mathrm{P} 59.9 \\
\mathrm{mg}, \mathrm{Cl} 127.0 \mathrm{mg} \text {. }\end{array}$} \\
\hline Vitamins & \multicolumn{5}{|c|}{$\begin{array}{l}\text { A } 232.4 \mathrm{IU}, \mathrm{B}_{1} 0.24 \mathrm{mg}, \mathrm{B}_{2} 0.27 \mathrm{mg}, \mathrm{B}_{6} 0.29 \mathrm{mg}, \mathrm{B}_{12} 0.37 \mu \mathrm{g} \text {, } \\
\text { C } 7.22 \mathrm{mg}, \mathrm{D} 15.2 \mathrm{IU}, \mathrm{E} 0.8 \mathrm{IU}, \mathrm{K} 70.9 \mu \mathrm{g} \text {, Niacin } 2.94 \mathrm{mg} \text {, } \\
\text { Folic acid } 28.1 \mu \mathrm{g} \text {, Pantothenic acid } 0.42 \mathrm{mg} \text {, Biotin } 4.6 \mu \mathrm{g} \text {. }\end{array}$} \\
\hline Trace element & \multicolumn{5}{|c|}{$\mathrm{Fe} 0.70 \mathrm{mg}, \mathrm{Zn} 1.06 \mathrm{mg}, \mathrm{Cu} 0.14 \mathrm{mg}, \mathrm{Mn} 0.18 \mathrm{mg}$} \\
\hline
\end{tabular}

* Medium-chain triglyceride.

Table 2. Fatty acids composition of MCT-rich oil in the experimental diets.

\begin{tabular}{llc}
\hline \multicolumn{1}{c}{ Source } & \multicolumn{1}{c}{ Fatty acids } & Composition (\%) \\
\hline MCT* & C 8:0 Caprylic acid & 45.0 \\
C10:0 Capric acid & 15.0 \\
Safflower oil & C16:0 Palmitic acid & 3.0 \\
& C18:0 Stearic acid & 1.0 \\
& C18:1 Oleic acid & 5.9 \\
& C18:2 Linoleic acid & 29.7 \\
& C18:3 Linolenic acid & 0.4 \\
\hline
\end{tabular}

* Medium-chain triglyceride.

Table 3. Enteral feeding schedule of the experimental diet.

\begin{tabular}{lrrrrrr}
\hline & \multicolumn{7}{c}{ Days after operation } \\
\hline Energy administration (kcal/day/rat) & 1 & 2 & 3 & 4 & 5 & 6 \\
Protein administration (g/day/rat) & 25 & 35 & 45 & 65 & 75 & 75 \\
\hline
\end{tabular}


On the last day, immediately after the enteral feeding, the rats were anesthetized with pentobarbital and blood was drawn from the abdominal vein. The serum was harvesed and analyzed for the following: albumin (bromocresol green method), total protein (Biuret method), triglycerides (free glycerol elimination method), nonesterified fatty acids (enzymatic method), phospholipids (enzymatic method), total cholesterol (enzymatic method), glutamic oxaloacetic transaminase (GOT; Karmen consensus method), glutamic pyruvic transaminase (GPT; Karmen consensus method) and alkaline phosphatase (ALP; Bessey-Lowry method) with an automatic analyzer (MODEL 7150, Hitachi, Ltd., Tokyo).

Liver lipid accumulation. The livers were collected, weighed, and their lipid (triglyceride, phospholipid, and total cholesterol) and protein contents were measured. The lipids were extracted from $1 \mathrm{~g}$ homogenized liver with a chloroform and methyl alcohol $(2: 1)$ mixture, and triglycerides, phospholipids, and total cholesterol were analyzed with an assay kit (Wako Pure Chemical Ind., Osaka, Japan).

Statistical analysis. The results are expressed as $\mathbf{M} \pm$ SEM of surviving rats. The group means were compared using analysis of variance (ANOVA) with Tukey's test. A $p$ value of 5\% was considered significant.

\section{RESULTS}

Effect of fat intake on liver lipid accumulation and liver function

Figure 2 shows the body weights of rats administered different amounts of fat in their diet. The mean body weight of each group decreased about $8 \%$ by POD 2 and, by POD 6, returned approximately to its POD 0 value. There were no

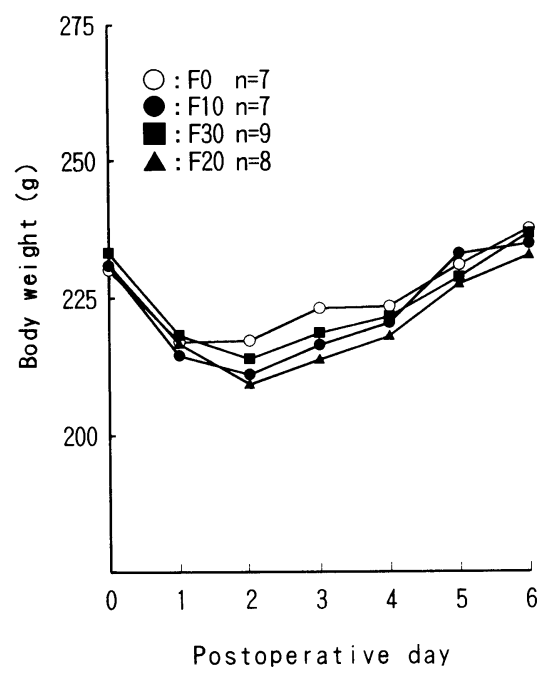

Fig. 2. Mean body weights of septic rats receiving diets containing different amounts of fat postoperatively. 
significant differences among the four groups on any day.

Absolute and relative liver weights are shown in Table 4. In contrast to body weights, liver weights differed significantly from each other among the four groups. The absolute liver weights of the F0 and F30 groups were significantly higher than those of the F10 and F20 groups. No significant difference was observed, however, between the relative liver weights of the F10, F20 and F30 groups. The relative liver weight of the F0 group was significantly higher than that of the other three groups.

Table 5 shows the triglyceride, total cholesterol, and phospholipid contents of the liver. The triglyceride and cholesterol contents, both per gram liver and per liver, showed an inverse dose-dependent response to the amount of dietary fat. The phospholipid content on the other hand, showed no significant differences among the four groups.

Serum GOT, GPT, and ALP activity, as indices of liver dysfunction, are shown in Table 6. Both GOT and GPT activities in the F0 group were about 3 or more times higher than in the other three groups. In our preliminary study, GOT and GPT activities of the same week-old normal rats fed a commercial rat diet were $79.5 \pm 14.1$ and $13.4 \pm 2.4 \mathrm{IU} /$ liter, respectively. The values of the F10, F20, and

Table 4. Absolute and relative liver weights in septic rats after 6 days of enteral feeding.

\begin{tabular}{ccc}
\hline \multirow{2}{*}{ Group } & \multicolumn{2}{c}{ Liver weight } \\
\cline { 2 - 3 } & $(\mathrm{g})$ & $(\mathrm{g} / 100 \mathrm{~g} \mathrm{B.W})$. \\
\hline F0 $n=7$ & $18.96 \pm 0.67^{\mathrm{a}}$ & $7.56 \pm 0.23^{\mathrm{a}}$ \\
F10 $n=7$ & $15.61 \pm 0.73^{\mathrm{b}, \mathrm{c}}$ & $6.48 \pm 0.28^{\mathrm{b}}$ \\
F20 $n=8$ & $15.39 \pm 0.36^{\mathrm{b}}$ & $6.12 \pm 0.14^{\mathrm{b}}$ \\
F30 $n=9$ & $17.34 \pm 0.75^{\mathrm{a}, \mathrm{c}}$ & $6.65 \pm 0.25^{\mathrm{b}}$ \\
\hline
\end{tabular}

Values are $\mathbf{M} \pm$ SEM. B.W.: Body weight just before dissection. a,b,c: Different superscript letters in the same column indicate a significant difference at $p<0.05$.

Table 5. Liver lipid content in septic rats after 6 days of enteral feeding of experimental diets.

\begin{tabular}{|c|c|c|c|c|c|c|}
\hline \multirow{2}{*}{ Group } & \multicolumn{2}{|c|}{ Triglyceride } & \multirow{2}{*}{\multicolumn{2}{|c|}{$\frac{\text { Cholesterol }}{(\mathrm{mg} / \mathrm{g} \text { liver })(\mathrm{mg} / \text { liver })}$}} & \multirow{2}{*}{\multicolumn{2}{|c|}{$\frac{\text { Phospholipid }}{(\mathrm{mg} / \mathrm{g} \text { liver })(\mathrm{mg} / \text { liver })}$}} \\
\hline & (mg/g liver) & (mg/liver) & & & & \\
\hline F0 $n=7$ & $88.4 \pm 11.8^{\mathrm{a}}$ & $1685.8 \pm 236.5^{\mathrm{a}}$ & $3.5 \pm 0.2^{\mathrm{a}}$ & $66.7 \pm 4.2^{\mathrm{a}}$ & $16.8 \pm 1.5$ & $318.9 \pm 31.0$ \\
\hline $\mathrm{F} 10 n=7$ & $40.7 \pm 6.0^{b}$ & $644.1 \pm 109.6^{b}$ & $3.0 \pm 0.2^{\mathrm{b}}$ & $47.2 \pm 3.4^{b}$ & $17.0 \pm 1.4$ & $263.0 \pm 20.1$ \\
\hline $\mathrm{F} 20 n=8$ & $23.4 \pm 1.9^{c}$ & $358.3 \pm 27.1^{\mathrm{b}, \mathrm{c}}$ & $2.2 \pm 0.1^{\mathrm{c}}$ & $33.5 \pm 0.8^{c}$ & $17.7 \pm 0.8$ & $271.2 \pm 12.6$ \\
\hline $\mathrm{F} 30 n=9$ & $17.7 \pm 1.6^{c}$ & $311.0 \pm 39.1^{c}$ & $1.8 \pm 0.0^{\mathrm{d}}$ & $30.8 \pm 1.4^{\mathrm{c}}$ & $14.4 \pm 0.8$ & $250.3 \pm 17.7$ \\
\hline
\end{tabular}

Values are $\mathbf{M} \pm$ SEM. ${ }^{\text {a, b,c,d }}$ Different superscript letters in the same column indicate a significant difference at $p<0.05$. 
F30 groups approximated those of nonseptic rats. ALP activities were also higher in the FO group than in the other three groups, but the difference did not reach statistical significance.

Effects of different amounts of fat intake on protein metabolism and nutritional status

Figure 3 shows the daily nitrogen balance, an index of nitrogen retention in the body. The nitrogen balance in all four groups was negative on POD 1 and positive POD 2 and thereafter. After POD 3, the F10 group value was the highest. On

Table 6. Serum GOT, GPT, and ALP activities in septic rats after 6 days of enteral feeding of experimental diets.

\begin{tabular}{cccc}
\hline Group & $\begin{array}{c}\text { GOT } \\
(\mathrm{IU} / \text { liter })\end{array}$ & $\begin{array}{c}\text { GPT } \\
(\mathrm{IU} / \text { liter })\end{array}$ & $\begin{array}{c}\text { ALP } \\
(\mathrm{IU} / \text { liter })\end{array}$ \\
\hline F0 $n=7$ & $391.7 \pm 128.6^{\mathrm{a}}$ & $31.2 \pm 5.9^{\mathrm{a}}$ & $489.7 \pm 73.8$ \\
F10 $n=7$ & $76.4 \pm 5.1^{\mathrm{b}}$ & $11.7 \pm 1.1^{\mathrm{b}}$ & $277.6 \pm 28.2$ \\
F20 $n=8$ & $111.9 \pm 17.2^{\mathrm{b}}$ & $16.6 \pm 2.6^{\mathrm{b}}$ & $374.8 \pm 92.1$ \\
F30 $n=9$ & $67.2 \pm 6.4^{\mathrm{b}}$ & $13.7 \pm 1.7^{\mathrm{b}}$ & $344.1 \pm 23.3$ \\
\hline
\end{tabular}

GOT: glutamic oxaloacetic transaminase, GPT: glutamic pyruvic transaminase, ALP: alkaline phosphatase. Values are $\mathbf{M} \pm$ SEM. ${ }^{a, b, c}$ Different superscript letters in the same column indicate a significant difference at $p<0.05$.

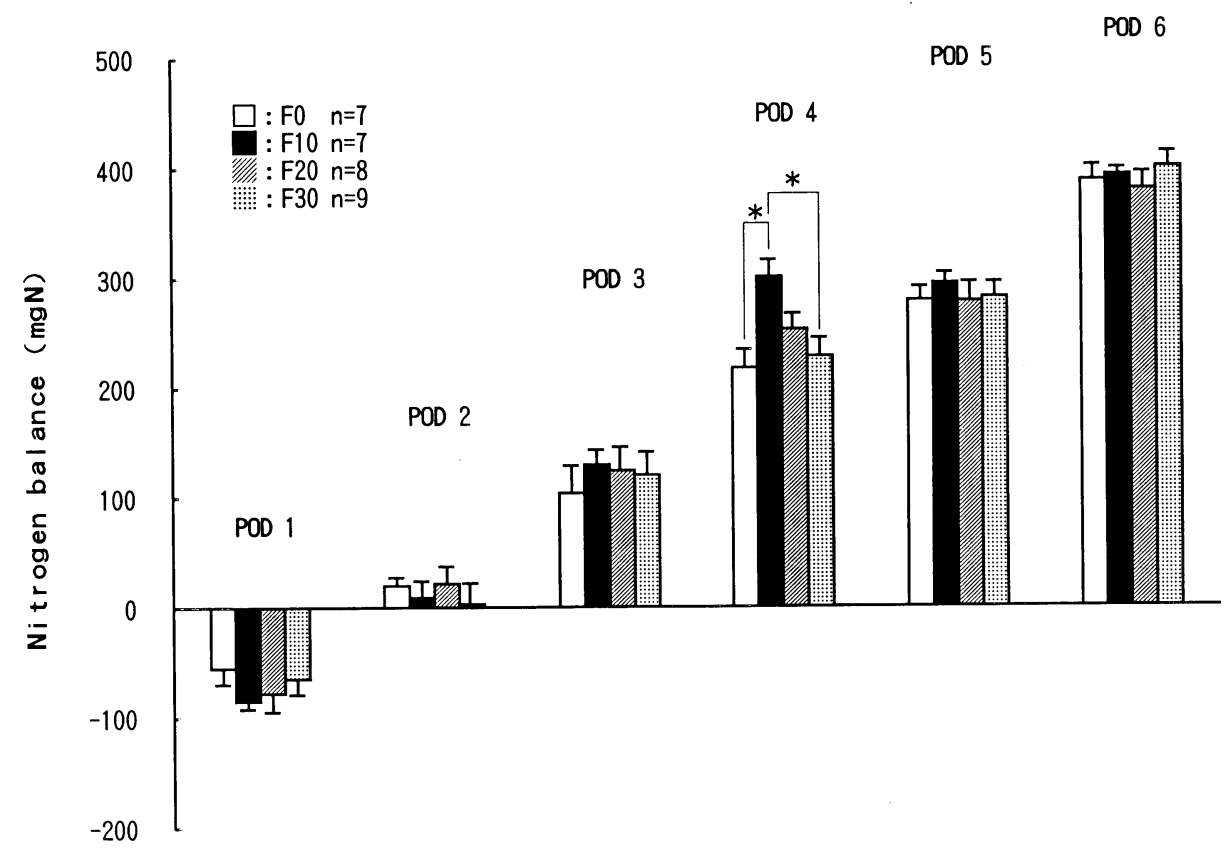

Fig. 3. Daily nitrogen balance of septic rats receiving diets containing different amounts of fat. Values are $\mathbf{M} \pm \mathbf{S E M}$. ${ }^{*} p<0.05$. 
POD 4, the F10 group value was significantly higher than that of the other groups. Serum total protein and albumin concentrations, important indices of protein metabolism and nutritional status in sepsis, are shown in Fig. 4. After 6 days feeding, serum total protein in the F10 group was highest, differing significantly from the F0 and F30 group values. The concentration of the F20 group was higher than that of the F0 and F30 groups but this was not statistically significant. The serum albumin concentration in the F10 group was also higher than in the other groups, and the difference between the F10 and F0 groups was significant.

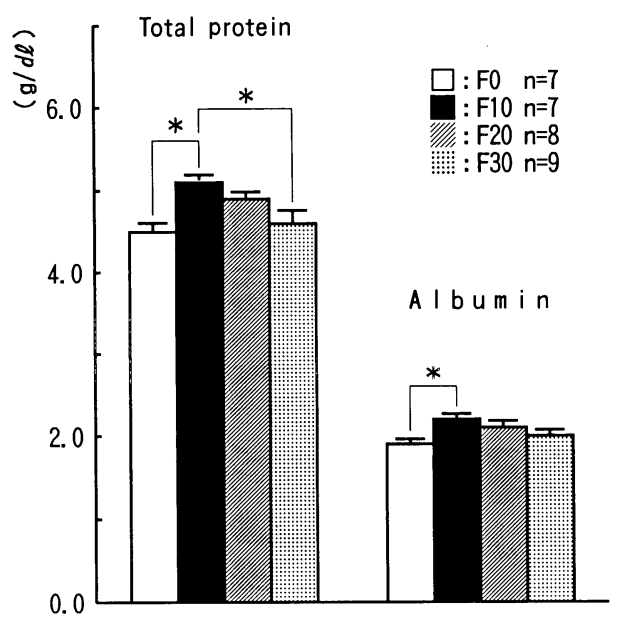

Fig. 4. Serum total protein and albumin in septic rats after 6 days of enteral feeding of experimental diets. Values are $\mathbf{M} \pm \mathrm{SEM} .{ }^{*} p<0.05$.
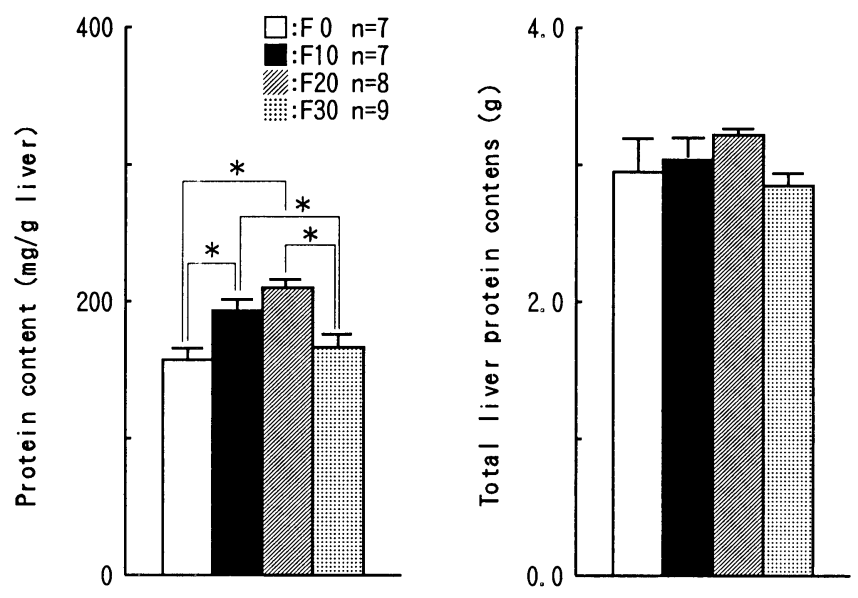

Fig. 5. Liver protein content in septic rats after 6 days of enteral feeding of experimental diets. Values are $\mathbf{M} \pm \mathbf{S E M} .{ }^{*} p<0.05$. 
Table 7. Serum lipid concentrations in septic rats after 6 days enteral feeding.

\begin{tabular}{ccccc}
\hline Group & $\begin{array}{c}\text { Triglyceride } \\
(\mathrm{mg} / \mathrm{dl})\end{array}$ & $\begin{array}{c}\text { NEFA } \\
(\mu \mathrm{Eq} / \text { liter })\end{array}$ & $\begin{array}{c}\text { Phospholipid } \\
(\mathrm{mg} / \mathrm{dl})\end{array}$ & $\begin{array}{c}\text { Total cholesterol } \\
(\mathrm{mg} / \mathrm{dl})\end{array}$ \\
\hline F0 $n=7$ & $21 \pm 9^{\mathrm{a}}$ & $104 \pm 20^{\mathrm{a}}$ & $75 \pm 18^{\mathrm{a}}$ & $33 \pm 9^{\mathrm{a}}$ \\
F10 $n=7$ & $61 \pm 6^{\mathrm{a}, \mathrm{b}}$ & $565 \pm 83^{\mathrm{b}}$ & $174 \pm 8^{\mathrm{b}}$ & $81 \pm 5^{\mathrm{b}}$ \\
F20 $n=8$ & $54 \pm 8^{\mathrm{a}}$ & $309 \pm 31^{\mathrm{c}}$ & $148 \pm 6^{\mathrm{b}, \mathrm{c}}$ & $70 \pm 4^{\mathrm{b}, \mathrm{c}}$ \\
F30 $n=9$ & $105 \pm 26^{\mathrm{b}}$ & $263 \pm 39^{\mathrm{c}}$ & $134 \pm 9^{\mathrm{c}}$ & $60 \pm 3^{\mathrm{c}}$ \\
\hline
\end{tabular}

NEFA: nonesterified fatty acids. Values are $\mathrm{M} \pm \mathrm{SEM}$. ${ }^{\mathrm{a}, \mathrm{b}, \mathrm{c}}$ Different superscript letters in the same column indicate a significant difference at $p<0.05$.

The concentration of liver protein, which is the main visceral protein, is shown in Fig. 5. The protein content per gram liver from the F10 and F20 groups was significantly higher than that of the F0 and F30 groups. Furthermore, the total liver protein content of the F10 and F20 groups tended to be higher than that of the F0 and F30 groups.

The effect of different amounts of dietary fat on serum lipid concentrations is shown in Table 7. The serum triglyceride concentration of the F30 group was notably higher than that of the other groups, differing significantly from the F20 and F0 groups. The serum nonesterified fatty acid concentration was lowest in the F0 group. Both the serum phospholipid and serum total cholesterol concentrations were lowest in the F0 group, and the 3 fat-fed groups showed an inverse dosedependent response to the amount of dietary fat.

\section{DISCUSSION}

Liver lipid accumulation (6) and liver dysfunction $(7,8)$ are frequently observed in sepsis, and carnitine, which carries fatty acids into the mitochondria, decreases markedly in muscle (2) and plasma (3). Because of these observations, it had been assumed that fat is not utilized effectively as an energy source in sepsis, and carbohydrate-based parenteral solution is used commonly for energy support for septic patients. There is a risk, however, that a large carbohydrate load could cause lipid accumulation in the liver and liver dysfunction $(14,15)$, so it is difficult in sepsis to supply sufficient energy by carbohydrate administration alone.

On the other hand, it was recently reported that fat is used adequately as an energy source during sepsis $(9,10)$, so the feeding of fat to the septic patient still remains controversial. In this study, we investigated the effects of fat administered enterally on liver and protein metabolism in septic rats because enteral nutrition has been reported recently to be more physiological and to enhance the gut's immunologic function compared to parenteral nutrition (16).

Sepsis was induced by the cecal ligation and puncture method described by Wichterman (13), and the necrotic cecum was removed. In our preliminary study, when the cecum was not removed, the 48 -h mortality rate was more than $90 \%$, 
which would have been too high for this study. With cecal removal, the average endotoxin concentration in blood was $275 \mathrm{pg} / \mathrm{ml}$ (nonseptic control, $8 \mathrm{pg} / \mathrm{ml}$ ), so we knew that this procedure would provide a model for sepsis.

We used MCT-rich oil as the experimental dietary fat source. Because MCT is oxidized independently of carnitine, Jensen et al. (17) suggested that MCT would be a promising fat substrate for septic patients who were short of carnitine. We previously reported that MCT was superior to long-chain triglycerides as an energy source in the septic rat (12). During enteral feeding, no severe diarrhea was observed in any of the groups, and fecal weights did not significantly differ among them on any day (data not shown). Therefore, it seems that the MCT-rich oil was absorbed sufficiently even when the diet contained 30\% fat.

The liver triglyceride (TG) content of the F0 group after 6 days was notably higher than that of the other groups. Hall et al. (14) reported that liver TG accumulation was observed in rats and patients administered excess carbohydrate (low fat diet), and other studies suggest that the conversion of glucose to fat is especially high in septic patients $(18,19)$. Therefore,the liver TG accumulation in the F0 group could have been caused by accelerated transformation of the excess dietary carbohydrate into TG.

On the other hand, hepatic lipase activity decreases in sepsis (5), and synthesis of TG from free fatty acids in the liver is elevated (6). The liver TG content of the F30 group, however, was similar to that of F20 group, showing that even a diet having $30 \%$ of its calories as fat may not cause TG accumulation in liver during enteral feeding of septic animals.

GOT and GPT activities (indices of liver dysfunction) in the F0 group were $391.7 \pm 340.3$ and $32.1 \pm 15.5 \mathrm{IU} / \mathrm{ml}$, respectively, notably higher than in the other groups. In our preliminary study, just before starting the enteral feeding, GOT and GPT activities were $182.7 \pm 41.4$ and $28.7 \pm 5.2 \mathrm{IU} / \mathrm{ml}$, respectively, in septic rats, and $79.5 \pm 14.1$ and $13.4 \pm 2.4 \mathrm{IU} / \mathrm{ml}$, respectively, in nonseptic control rats. Therefore, it seems that the liver dysfunction was aggravated by the feeding. Liver dysfunction is observed frequently during sepsis due to the effect of endotoxin on liver cells $(7,8)$. The result in the F0 group could have been caused by liver lipid accumulation and/or incomplete recovery from endotoxin damage. At the same time, GOT and GPT activity in the other groups decreased to the range of the nonseptic control rats. Since the intake of calories, nitrogen, and other nutrients were equal in all groups, it is clear that the fat was responsible for the supression of liver dysfunction in the septic rats.

The most salient features of sepsis are the accelerated breakdown of muscle protein, the increase of nitrogen excretion, and the decrease of blood albumin concentration (20). These phenomena indicate that body protein is being catabolized to supply energy. We investigated the effect of different amounts of fat administration on protein metabolism in septic rats.

The daily nitrogen balance in the F10 group tended to be higher than in the F0 and F30 groups, and the liver protein concentration in the F10 and F20 groups was 
notably higher than in the F0 and F30 groups. These results indicate that nitrogen retention in the F10 and F20 groups was higher than in the other groups, and the optimal amount of dietary fat for body protein-sparing may range from 10\% to $20 \%$ of total calories. The protein-sparing effect of fat administration in sepsis and surgical stress, however, still remains controversial (21). Several investigators have indicated that the major portion of the fuel oxidized is fat, and fat should be the natural source of nonprotein energy in severe surgical stress $(9,10)$. Others have suggested, in contrast, that dietary fat does not reduce nitrogen loss, and that carbohydrate significantly reduces nitrogen excretion (21). In this study, serum TG, which is not oxidized directly in peripheral tissue, in the F30 group, was about 2 times higher than in the F10 and F20 groups. This result suggests that $30 \%$ of total calories as fat is excessive, even if MCT-rich oil is used,and the protein-sparing effect is influenced by the dietary fat/carbohydrate ratio.

The concentrations of serum albumin and total protein in the F10 and F20 groups were significantly higher than in the F0 group, and they were related to liver protein content. This suggests that the administration of fat as $10 \%$ to $20 \%$ of total calories might increase the albumin synthesis of liver in septic rats. Skillman et al. (22) reported a higher rate of albumin synthesis in parenterally fed surgical patients who received fat compared to those who received glucose. They also suggested that fat intake tended to favor the synthesis of visceral protein in those patients. In general, nonesterified fatty acid concentration in blood decreases during sepsis in man and in experimental animals. Wannemacher et al. (19) reported that the decrease could be a consequence of an infection-induced decrease in plasma albumin, which is the fatty acid carrier. The albumin-bound free fatty acids are only one source of oxidizable fatty acid substrates for peripheral tissues (23). In the present study, the groups with higher serum albumin concentrations, F10 and F20, also had higher serum nonesterified fatty acid concentrations, so the administrated fat could be used effectively in peripheral tissues as an energy source in these groups.

In conclusion, enteral fat administration in septic rats as $30 \%$ of total calories reduced liver lipid accumulation and liver dysfunction, but might have been excessive for optimal protein metabolism. Therefore, the preferable amount may range from $10 \%$ to $20 \%$ of total calories.

\section{REFERENCES}

1) Elwyn, D. H., Kinney, J. M., and Askanazi, J. (1981): Energy expenditure in surgical patients. Surg. Clin. North. Am., 61, 545-556.

2) Border, J. R., Burns, G. P., Rumph, C., and Schenk, W. G. (1970): Carnitine levels in severe infection and starvation, a possible key to prolonged catabolic state. Surgery, 68, 175-179.

3) Nanni, G., Pittiruti, M., Giovannini, I., Boldrini, G., Ronconi, P., and Castagneto, M. (1985): Plasma carnitine levels and urinary carnitine excretion during sepsis. J. 
Parenter. Enter. Nutr., 9, 483-490.

4) Robin, A. P., Askanazi, J., Greenwood, M. R. C., Carpentier, Y. A., Gump, F. E., and Kinney, J. M. (1981): Lipoprotein lipase activity in surgical patients, influence of trauma and infection. Surgery, 90, 401-408.

5) Meraihi, Z., Lutz, O., Scheftel, J. M., Frey, A., and Bach, A. C. (1990): Gramnegative bacteria sepsis in the rat and tissue lipolytic activity on LCT and MCT/LCTbased commercial parenteral emulsions. Infusionstherapie, 17, 104-107.

6) Lanza-Jacoby, S., and Tabares, A. (1990): Triglyceride kinetics lipoprotein lipase, and liver lipogenesis in septic rats. Am. J. Physiol., 258 (Endocrinol. Metab. 21), E678-E 685.

7) Smirniotis, V., Lambrou, A., Kourias, E., and Androulakis, G. (1990): Glucose-based versus fat-based total parenteral nutrition (TPN). Clin. Nutr., 9, 234-236.

8) Utili, R., Abernathy, C. O., and Zimmerman, H. J. (1976): Cholestatic effects of Escherichia coli endotoxin on the isolated perfused rat liver. Gastroenterology, 70, 248-253.

9) Nanni, G., Siegel, J. H., Coleman, B., Fader, P., and Castiglione, R. (1984): Increased lipid fuel dependence in the critically ill septic patient. J. Trauma, 24, 14-30.

10) Shaw, J. H. F., and Woffe, R. H. (1985): Response to glucose and lipid infusions in sepsis, a kinetic analysis. Metabolism, 34, 442-449.

11) Bach, A. C., and Babayan, V. K. (1982): Medium-chain triglycerides, an update. Am. J. Clin. Nutr., 36, 950-962.

12) Hayashi, N., Kashiwabara, N., Yanai, M., Kawanishi, G., and Yamakawa, M. (1989): Absorption and oxidation of medium-chain triglyceride and long-chain triglyceride in rats with peritonitis and effect of carnitine supplementation. Nippon Eiyō Shokuryō Gakkaishi (J. Jpn. Soc. Nutr. Food Sci.), 42, 441-448.

13) Wichterman, K., Baue, A. E., and Chaudry, I. H. (1980): Sepsis and septic shock, a review of laboratory models and a proposal. J. Nutr. Res., 29, 189-201.

14) Hall, R. I., Grant, J. P., Rose, L. H., Coleman, R. A., Bozovic, M. G., and Quarfordt, S. H. (1984): Pathogenesis of hepatic steatosis in the parenterally fed rat. J. Clin. Invest., 74, 1658-1668.

15) Kaminski, D. L., Adams, A., and Jellinek M. (1980): The effect of hyperalimentation on hepatic lipid content and lipogenic enzyme activity in rat and man. Surgery, 88, 93100.

16) Nirgiotis, J. G., and Andrassy, R. J. (1994): Bacterial translocation, in Enteral Nutrition, ed. by Borlase, B. C., and Blackburn, G. L., Chapman, New York, pp. 1524.

17) Jensen, G. L., Mascioli, E. A., Seidner, D. L., and Bistrian, B. R. (1990): Parenteral infusion of long- and medium-chain triglycerides and reticuloendothelial system function in man. J. Parenter. Enter. Nutr., 14, 467-471.

18) Long, C. L. (1977): Energy balance and carbohydrate metabolism in infection and sepsis. Am. J. Clin. Nutr., 30, 1301-1310.

19) Wannemacher, R. W., Pace, J. D., Beall, F. A., Dinterman, R. E., Petrella, V. J., and Neufeld, H. A. (1979): Role of the regulation of ketone body production during sepsis. J. Clin. Invest., 64, 1565-1572.

20) O'Donnell, T. F., Clowes, G. H. A., Blackburn, G. L., Ryan, N. T., Benotti, P. N., and Miller, J. D. B. (1976): Proteolysis associated with a deficit of peripheral energy fuel 
substrates in septic man. Surgery, 80, 192-200.

21) Jeejeebhoy, K. M. (1985): Carbohydrate-lipid utilization, in Nutrition in Clinical Surgery. 2nd edition, ed. by Wolfe, M. B., Ruderman, R. L., and Pollard, A., The Williams \& Wilkins, Co., Baltimore, pp. 121-130.

22) Skillman, J. J., Rosenoer, V. M., Pallota, J. A., Young, V. R., and Munro, H. N. (1981): Effect of isocaloric fat or glucose on albumin synthesis and nitrogen balance in patients receiving amino acid infusion. Surgery, 89, 168-174.

23) Spitzer, J. J., Bagby, G. J., Meszaros, K., and Lang, C. H. (1988): Alterations in lipid and carbohydrate metabolism in sepsis. J. Parenter. Enter. Nutr., 12 (Suppl), 53S-58S. 